\title{
The 38th Albi-Moissac Colloquium of French semioticians: Living beings and their environment
}

\section{Pauline Delahaye ${ }^{1}$}

From 2 to 5 July 2018, the 38th Albi-Moissac Colloquium took place in France. The CAMS/O - Semiotics Mediation Observatory for Albi Colloquium (Colloque Albi Médiations Sémiotiques/Observatoire), a French organization of semioticians, has been organizing the colloquium since 1980 . The annual event is alternately hosted by the towns of Moissac and Albi. Even if the colloquium itself has quite a long history, it included almost no talks on biosemiotics or zoosemiotics until this year, choosing to stick with the classic French semiotics tradition of Saussure and Greimas.

This year, the semiotics colloquium was entitled "Living beings and their environment", and its aim was to have biology, ethology and semiotics represented. Knowing the traditional difficulty when it comes to involving humanities in biological studies - and the other way around -, this colloquium was a good opportunity to obtain an overview of the position of semiotics in the French academic world in general, and of the interaction between semiotics and biology in particular.

I will not report all the participants' presentations here, for two main reasons. The first one is that this colloquium included training for doctoral students writing semiotics theses, no matter what their exact subject was. This training offers to $\mathrm{PhD}$ students a discussion space where they can present their work in progress. For most of them, it is their first time presenting their work in front of an academic audience, who then can give them advice and comments. Thus, some of these presentations had no connection to the main colloquium's subject, and instead were just work-in-progress presentations submitted to experienced specialists. The second reason is that the colloquium allows presentations in three different languages - in theory, there are four, but Spanish was not represented this year. I am a French native speaker who has no problem with following English, but I

1 EA 4509 - Sens, Texte, Informatique, Histoire; Sorbonne University, Paris, France; e-mail: delahayepauline@gmail.com. 
am unable to understand Italian properly. Therefore, I am not commenting on the work of Maddalena De Bernardi, Roberto Bertolotti and Luigi Virgolin - my apologies for this ${ }^{2}$.

The first point of interest is the fact that a significant number of presentations seven of the seventeen I can comment on - were exclusively human-oriented. This is not really surprising, considering the very textual tradition in semiotics that used to be predominant in France - and, to a lesser extent, Italy. Still, in the specific context of this colloquium with such an interdisciplinary theme and half of its academic committee coming from biology or ethology, this number necessarily appears as representative indeed of the actual academic orientation of semiotics in France: it remains a humanities field, deeply linked with text, human speech, and human behaviour.

Another point of interest is that, even in presentations involving other species, biosemiotic theories, or simply a non-human-centred question, the interaction between semiotics and biology was sometimes looked at with skepticism. Of course, this position is not necessarily a sign of hostility. We can just see that several biosemiotic theories or works are still poorly known in France, probably due to the particular academic tradition, but also to a certain kind of logocentrism, and the lack of French translations available for most of these works. This could also explain why most of the presentations rely on the concepts of Greimas and Saussure, while Peirce is almost totally absent. Nevertheless, this position allowed for some interesting papers to be presented. For example, Jean-François Gérard and Marie-Line Maublanc's work on how to read animal behaviour and its links with the environment in a semiotic way, asking if the classic "problem solving" way of thinking is, first, the only one, and second, the best one. In a rather similar way, Jacques Fontanille proposed seeing Jakob von Uexküll's interaction semiotics as a narration semiosis, alternating signs and tone - which is not, here, a proper sign.

Very few speakers seem to position themselves as real opponents to biosemiotics. Dario Martinelli, for example, proposed a talk titled after a sentence by Hoffmeyer - "Biology is immature biosemiotics", adding "...or the other way round?". He remarked that, throughout its history, biosemiotically inclined researchers have at times endorsed anti-Darwinist and pro-intelligent-design positions, and he also expressed reservations about some of Sebeok's work. While this critique may or may not have been addressed towards the biosemiotic field as a whole, it must be remarked that Martinelli mostly referred to texts and papers preceding the most recent developments in the field, and so it is not entirely clear whether he also intended to make a point on contemporary biosemiotics.

2 A summary of their contributions can be found on the colloquium website: http://mediationsemiotiques.com/resumes-2018. 
Still, besides these few cases, many of the presentations concerning other species, biosemiotic theories or non-human only questions were made by biosemiotics enthusiasts. Some of them had included biosemiotics not as a main field in their work, but as an interesting complementary tool for the investigation of various subjects and issues. Alessandro Zinna presented the growing interest in biology and semiotics as interdisciplinary subjects in France, adding that the impossibility of the total separation of human beings from other species forces one to think of a more global semiotics of the living, and to leave the traditional, textual-only attitudes in semiotics behind. Marie Renoue's presentation on mimicry and adaptation showed that new perspectives in biology, ecology and ethics can emerge from the meeting of semiotics and biology on this issue. Proceeding from the opposite perspective - from biology to semiotics - Corrado Sinigaglia explained how a neurobiological phenomenon, the motor representation, can be understood differently when also adding semiotics tools.

Some of the speakers were even more enthusiastic, linking semiotics and biosemiotics as a real new way of studying existing problems, and a field allowing for new subjects. For example, Ferrari Pier Francesco works on cortical motor organization, and a biosemiotic point of view allows him to propose an embodied language's evolutionary perspective, while Pascal Carlier uses semiotic methodology to question the concept of instinct and how scientists interact with it. Gianfranco Marrone gave one of the few - together with mine - talks on zoosemiotics, analysing the orangutan's emotions, while Veronika Estay Strange and Audrey Moutat presented a very interesting comparative semiotic study of the concept of the symbolism of rhythm in human beings, animals, and human-animal interactions.

To conclude, there were many very interesting presentations given at the colloquium, either as studies in biosemiotics or as explanations of why some researchers are still sceptical about biosemiotics. It is an overwhelming point that the encounter between biology and semiotics produces so many debates, propositions, oppositions and subjects. Semiotics in general, and biosemiotics in particular, is still not very common in France, but this kind of colloquium shows that the situation is changing, fields are shifting and the boundaries of academic traditions are blurring. Increasingly more contacts are created between France and other countries in the fields of semiotics, biosemiotics, and zoosemiotics. As a speaker at this colloquium and a permanent member of the French Zoosemiotics Society, I am happy that such an event occurs, and I believe that this promotion of a more interdisciplinary and international aspect of the field will lead us to a better understanding of the role that semiotics plays in the existence of living beings. 